\title{
Trends in smoking during pregnancy in England, 1992-7: quota sampling surveys
}

\author{
Lesley Owen, Ann McNeill, Christine Callum
}

Health Education Authority, Trevelyan House, London SW1P 2HW

Lesley Owen, senior research manager

Ann McNeill, strategic research adviser

Christine Callum, statistician

Correspondence to: Dr Owen lesley.owen@ hea.org.uk

BMJ 1998;317:728
The dangers of smoking during pregnancy are widely established. ${ }^{1}$ The Health of the Nation set the following target: "In addition to the overall reduction in [smoking] prevalence, at least a third of women smokers to stop smoking at the start of their pregnancy by the year 2000." As part of a smoking and pregnancy initiative, the Health Education Authority for England carried out a series of annual surveys of pregnant women starting in 1992 to measure knowledge, attitudes, and behaviour in relation to smoking during pregnancy.

\section{Subjects, methods, and results}

Seven surveys of pregnant women have been carried out. Two surveys were carried out in 1992 before and immediately after press advertising aimed at reducing smoking in pregnancy. All subsequent surveys followed similar press advertising carried out annually in March. Sample sizes from 1992 to 1997 were 625, 606, 526, $1039,1002,1004$, and 1018, the increase in later years being made possible by increased funding. Quota sampling was chosen as the most cost effective means of obtaining a representative sample of pregnant women, although it is not as rigorous as probability sampling. Interviewing at home was adopted in preference to contact through, for example, antenatal clinics to prevent bias in the resulting sample. Weighting was applied to ensure that all samples were consistent with the age distribution of live births for each year except the seventh, which was based on data for 1996 as those for 1997 were not available. Full details of sampling and methods are published elsewhere. ${ }^{3}$

The prevalence of smoking in 1997 was similar to that in 1992 (figure). The highest rate among younger pregnant women reflects, in part, differences in the social class composition of each age group: around three quarters of women aged 15-24 were from manual and unemployed groups compared with around three fifths of those aged 25-29 and around two fifths of those aged 30 or more. Among women who were smoking before their pregnancy, rates of stopping averaged $10 \%$ immediately before pregnancy and 18\% during pregnancy (unweighted base for surveys $1-7=2106$ ). In this same group rates of cutting down averaged about $4 \%$ immediately before pregnancy and 32\% during pregnancy. However, rates of stopping within surveys varied as a function of duration of the pregnancy. In $1997,50 \%$ of the women surveyed were in the third trimester. Of those who were smokers (unweighted base $=196$ ), 14\% smokers stopped in the first trimester, $2 \%$ in the second, and 2\% in the third. Thus most women who stop smoking during pregnancy do so in the first trimester.

\section{Comment}

The prevalence of smoking and rates of stopping or cutting down on smoking have changed little since 1992. Smoking during pregnancy is a problem particularly for

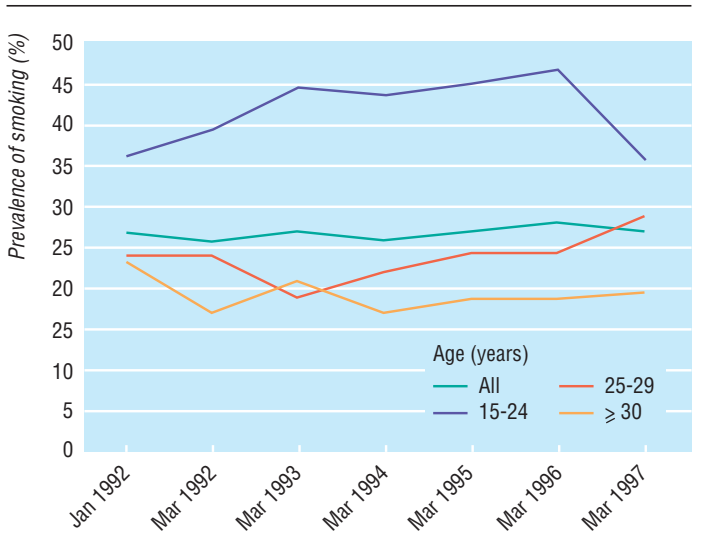

Prevalence of smoking among pregnant women by age, England 1992-7. Denominators are all pregnant women in relevant year. Percentages are weighted to age distribution of live births

those who are young, unemployed, or from manual groups. Around 1 in 10 pregnant women gave up smoking immediately before they became pregnant, and more than 1 in 6 gave up during pregnancy. Together, these figures (28\%) fall short of the Health of the Nation's requirement that a third of pregnant women stop smoking at the start of pregnancy. ${ }^{2}$ We did not use a biochemical measure to validate smoking status, so our findings are likely to be conservative.

Our data differ considerably from those reported in the infant feeding survey, ${ }^{5}$ perhaps because of differences in methods. The infant feeding survey was a retrospective survey using postal questionnaires of women who had recently given birth; it covered the United Kingdom and determined rates of stopping smoking indirectly through cigarette consumption.

Our findings suggest that current practice to reduce smoking during pregnancy is either not working or lacks sufficient investment and prioritisation to be effective.

We thank Keith Bolling, research manager at the Health Education Authority, for his involvement in some of the surveys. We also thank National Opinion Poll for fieldwork and data collection.

Contributors: LO had the original idea for the study, had overall responsibility for the surveys, identified and helped with the analyses, and co-wrote the paper. $\mathrm{AMcN}$ contributed ideas, co-wrote the paper, and made suggestions for analyses. CC analysed the data. All authors are guarantors for the study.

Funding: This research was funded by the Department of Health as part of an ongoing contract with the Health Education Authority to contribute towards reducing the prevalence of smoking.

Conflict of interest: None.

1 Royal College of Physicians. Smoking and the young. London: RCP, 1992

2 Department of Health. Health of the nation: a strategy for health in England. London: HMSO, 1992

3 Campion P, Owen L, McNeill A, McGuire C. Evaluation of a mass media campaign on smoking and pregnancy. Addiction 1994;89:1245-54.

4 Campion P, Owen L, McNeill A. Smoking before, during and after pregnancy in England. Health Educ J 1994;53:163-73.

5 Foster K, Lader D, Cheeseborough S. Infant feeding 1995. London: HMSO, 1997.

(Accepted 2 June 1998) 